\title{
UNCTAD's failures: the rich get richer Robert Ramsay
}

The recent failure of the sixth conference of the United Nations Conference on Trade and Development (UNCTAD) at Belgrade came as no surprise to most observers. It is common knowledge that UNCTAD has failed to do what it was set up to do-to narrow the ever-widening gap between rich and poor countries. There has, however, been remarkably little examination of the real reasons underlying its failure, least of all by the Brandt Commission. Yet an understanding of just why UNCTAD has failed throws considerable light on the general decline of the North-South debate. In particular, it casts considerable doubt upon the validity of trying to rectify the maldistribution of wealth between rich and poor countries without examining the maldistribution of wealth between rich and poor people. Is the lack of any real probe into UNCTAD just an accidental omission, or is there a reluctance to face the unpalatable facts that underlie the organization's failure?

Most people who have had contact with UNCTAD write it off as a bizarre institution that deals in generalities. Its bizarre nature became all too apparent at its previous conference (UNCTAD V, in 1979), when five thousand people assembled in Manila under the most lavish conditions imaginable - for a discussion on world poverty. The contradiction was accentuated by the nebulosity of the policy speeches, and by the manner in which the speakers all congratulated one another and applauded each others' platitudes. By the end of UNCTAD V, the deficiencies of the organization were obvious-yet when delegates met to review the situation they made no real proposals for change. Government representatives renewed the contract of the Secretary General,

These views stem largely from sixteen years' involvement with UNCTAD, initially as a delegate for Australia, subsequently on field assignments in developing countries, and for the past eight years in Geneva in charge of the section that handles political shipping issues. The activities of the UNCTAD Committee on Shipping provide a penetrating insight into the NorthSouth dialogue because shipping is one of the few areas in which UNCTAD has moved from generalities to specifics. Consequently, shipping provides one of the best indicators of resistance to change.

International Organization 38, 2, Spring $1984 \quad 0020-8183 / 84 / 020387-10 \quad \$ 1.50$ (c) 1984 by the Massachusetts Institute of Technology and the World Peace Foundation 
which was tantamount to expressing their satisfaction with the way the organization was functioning, or failing to function.

At Belgrade, the policy speeches were just as nebulous, but the applause and congratulatory statements died down after the first day or two: people simply abandoned the pretense of a great success. All the same, it would be surprising if delegates were to make any real proposals for change following Belgrade.

The failure of UNCTAD is often attributed to the "group system" (whereby the arguments advanced are those of groups of countries and not those of individual countries) and to the inefficiency of the UNCTAD secretariat. Both these factors do call for comment, but what really needs examining is not so much the failure of UNCTAD as the failure of governments-of rich and poor countries alike-to show any real concern. It is this latter failure which illuminates not only the relationship between North and South but also the relationship between rich and poor people.

\section{The group system}

The member states of UNCTAD are grouped into three "political parties." Group $B$ is comprised of the industrialized countries, members of the OECD; the Group of 77 is comprised of the developing countries (being a fusion of Groups $\mathrm{A}$ and $\mathrm{C}$, which covered developing countries in different regions); and Group D's members are the socialist countries of Eastern Europe. There are also a couple of "independent members," China and Israel. Within the groups, there are enormous differences. Even in Group B, levels of prosperity and economic systems differ to a marked degree; the common factor is that all members are relatively prosperous market-economy countries. The Group of 77 embraces a much more diverse collection of countries, ranging from the oil-producing countries, through rapidly industrializing countries like India and Brazil, to small impoverished countries like Nepal and Niger. The one thing these countries have in common is that they all classify themselves as "developing."

Unlike most national political parties, these international parties lack any coherent political philosophy. Logically, the Group of 77 might be expected to produce a body of proposals, but interests within the group are so divergent that the member countries can usually reach a uniform position only by phrasing their proposals in terms so general that they could not be used as a basis for serious negotiations. In fact, it is no secret that many of the 77 speakers who made "demands" at UNCTAD VI were aiming to produce press reports for domestic consumption rather than to provoke international discussion. Besides, the Group of 77 has one serious disadvantage when it comes to policy making: it has no secretariat.

The Group B countries generally confine their role to opposing any proposal 
for change. Although most of them realize that a more equitable distribution of wealth would be in the long-term interests of a healthy world economy, in the short term any change would adversely affect some of the B countries. The ones likely to be affected call for, and obtain, the support of the others in the name of "Group solidarity" (it being understood that on some future occasion reciprocal support will be obtained). Even when the Group B countries put forward "positive proposals" of their own, these are usually of a cosmetic nature designed to conceal their underlying resistance to change.

The Group D countries play very little part in the North-South debate. The problems, they claim, are attributable to the former colonial activities of the Group B powers (and to the current activities of the Group B corporations). They are consequently a matter for settlement between $B$ and the 77 . Nevertheless, the D countries generally support the 77 , as does China.

Thus, if any specific proposals are to come forth, they could only come from the international civil servants who comprise the UNCTAD secretariat. But whereas national civil servants work to the instructions of the politicians in power, on the international scene there is no party in power and there is no cabinet to direct policy; the UNCTAD secretariat works on its ownoften with peculiar results, and frequently with no results at all.

UNCTAD could have become a better forum for debating North-South issues had it been equipped with a competent secretariat to produce sound policy proposals. Unfortunately, most of the secretariat's reports have been notable for little but their length, verbosity, and obscurity, often being issued too late to be even read, let alone considered, before the relevant meetings.

Insofar as it has ennuciated any general philosophy, the secretariat has talked about the need to "change the structure of the world economy" and proposed "development strategies" to bring about a "New International Economic Order" (but all in the vaguest terms). Few of the secretariat's proposals have served as a basis for taking specific action. As an inevitable consequence, most UNCTAD discussions have degenerated into an exchange of generalities. Even when the secretariat has proposed specific action, its proposals have read far too much like election speeches. Promising too many things to too many people, proposals emphasize advantages and ignore disadvantages instead of arguing the pros and cons of different courses of action, which is so essential for sound policy formulation.

Although UNCTAD officials talk of their various successes over the years in the form of international conventions, agreements, and resolutions, most of these contain more than a fair quota of vague language, and much of the consensus relates to minor rather than major matters. The "successes" have a certain value in demonstrating the procedures that could be used if ever governments were to get down to serious business, but considerably less value from the point of view of substance. 


\section{Problems in the secretariat}

Among government delegates, it is common to attribute UNCTAD's failure to the failure of the secretariat, but, as already noted, the real question relates to the lack of any move by governments to change the secretariat.

When the secretariat was set up, what was needed was a small, cohesive body of senior officials who could clarify the issues in different sectors of the world economy and point out what could, and what could not, be achieved by intergovernmental action. It was essential that the top officials be know/edgeable not only as regards specific sectors of the economy but also as regards the way in which governments function. They had to be people, that is, with some appreciation of the difference between an academic thesis and a policy proposal upon which governments can take action, and also people with some basic administrative ability.

As it turned out, the qualities most needed were the most lacking. The high salaries and diplomatic status inevitably attracted individuals who were more interested in the salary and status than in the job itself. Many officials treated their Geneva appointments as little more than a comfortable way of spending their last years before retirement.

As a result, the secretariat has been not so much administered as allowed to drift. People have been hired with no real qualifications to serve the organization; others have been engaged to undertake assignments that could not possibly serve the organization's aims; others have arrived at the Palais des Nations to find themselves pitifully underemployed. Staff are permitted to develop all sorts of proposals for "further studies," proposals that are designed to serve not so much the interests of the developing countries as the personal needs of the staff in justifying extensions of their employment contracts. Vast sums of money are wasted on unnecessary work (and on paying people who do not really work at all), and on the inevitable worldwide air travel to which so many UN officials become addicted. But at the same time, there is considerable penny-pinching in areas where expenditure is really needed: professional staff have to work without even the most elementary reference facilities.

The result is the well-known stream of poor-quality documentation that flows into the in-trays of government delegates. Many of these reports should have been suppressed without being submitted, but senior officials tend to insist on publishing everything that can be published - as if the sheer volume of paper were an indicator of productivity. Yet the obscurity that permeates so many reports may not be entirely accidental: many officers feel, at least subconsciously, that if they are obscure, no one will ever be quite sure just what they are saying, and hence no one will ever say that their findings are wrong. The same attitude applies to the length of documents and the delays: if delegates receive long documents at the last minute, there is a fair chance that they will never read them-and hence not criticize their authors. Even 
more serious, though, is the tendency of the top officials to tamper with the few good reports that are produced. Being political survivalists at heart, they erase points that might cause difficulties for particular countries (and hence the "election speech" character of so many UNCTAD reports).

As in other UN bodies, there is virtually no internal evaluation. The work of staff members is periodically evaluated on several counts and must be rated according to the standard UN ratings of Outstanding, Very good, Adequate, Somewhat below standard, and Poor. However, supervisors have been instructed that "Adequate" is deprecatory and would give a staff member the right of appeal, so even officials who can recognize poor work when they see it end up by rating all staff work as "Outstanding" or "Very good."

Faced with a growing reputation for inefficiency, many of the top officials do what incompetent civil servants do all over the world: they turn to matters of organization and procedure. But, as always, no amount of reorganization can compensate for a basic lack of competence. At the same time, many officials turn away from the policy issues for which the organization was established and bury themselves in technical assistance projects. Most of these projects are of dubious value to the recipient developing countries but of decided financial value to the bureaucrats and to the vast army of "experts" who have made technical assistance their profession.

The growing inefficiency of the secretariat has been accompanied by a decline in the number and the caliber of delegates attending UNCTAD meetings. Governments see little point in sending large numbers of highcaliber people to discuss the sort of generalities tabled for consideration. There has been a marked tendency to leave attendance to Geneva-based staff, who are inevitably jacks-of-all-trades who cannot discuss specific subjects in depth. Delegates from the capitals are much more numerous in summer than in winter, which suggests that some may not be traveling to Geneva to attend the UNCTAD meetings so much as using UNCTAD as an excuse to take trips to Europe. In turn, the decline in delegate quality has had an adverse effect upon the secretariat, as officials see little point in producing in-depth proposals for discussion by generalists. A vicious circle of cause and effect has set in, leading to the organization's ever-increasing ineffectiveness.

\section{Inaction in the member governments}

However, all of these facts have been well known to government delegates for some time-and, it must be presumed, to government officials in the capitals. The laxity of work in Geneva's Palais des Nations has even been described in vivid terms in the press. Why, then, are there no signs of concern?

From time to time, delegates from countries that supply most of the funds 
(such as the United States) complain of the expense and wastage - but always in such a way as to suggest that they want to have a complaint on record rather than any real investigation and change. When delegates met to review the debacle of UNCTAD V, they made a number of proposals: for example, that the secretariat's future reports should be short (32 pages), action-oriented, and issued "on time." But these demands had been made so many times before, and ignored so many times, that the likelihood of any change was minimal. Besides, the delegates' idea of getting documents "on time" is that governments should receive them six weeks before a meeting, which is totally insufficient for the formulation of a national viewpoint on any issue of significance. Did the delegates not expect (or did they not want) the secretariat to come up with any propoals of significance?

All the evidence points to an overwhelming desire on the part of governments to prevent any change in the status quo, under which rich people get steadily richer and poor people, at least comparatively, get steadily poorer. The attitude of the Group B countries is both evident and comprehensible, since these are the countries that would suffer from any change. What is harder to understand, even allowing for the divergent interests that make it difficult for the Group of 77 to arrive at a common policy, is the 77's restraint in pressing for changes in the economic system that keeps their countries in a state of poverty. Occasionally, delegates from the 77 deliver a forceful opening statement, which suggests that they are about to move from generalities to specifics, but then fail to follow it up. Like the American delegates who complain about wastage, the 77 often give the impression of wanting to get a statement on record rather than to bring about any real change. Thus, in many UNCTAD debates, one sees the Group B countries defending the status quo, the 77 refraining from attacking it, and Group D sitting and watching.

The Group B countries have an easy task in defending the status quo in sectors where the proposals consist of generalities. All they have to do is to respond with their own, equally vague, generalities and they can be sure that nothing concrete will emerge. It is when specific proposals are advanced that the true intensity of Group B's opposition to change becomes apparent.

For the most part the B government delegates respond to specific arguments with evasive generalities. Professing to agree on the need for reaching an international consensus, they fail to show any signs of being prepared to accept a consensus on any terms but their own. The more reactionary statements are generally made by business organizations (which have been known to distort proposals to make them easier to attack). In private discussion, the government delegates dissociate themselves from organizations that "only speak for the private sector," yet in their public statements they never give any indication that they are not in entire agreement.' spread of their membership) have official consultative status with UNCTAD; otherwise, they 
Outside the conference rooms, the Group B countries go further. They have been known to send envoys to complain to governments of developing countries whose delegates they regard as troublemakers. Some have even involved "difficult" governments in potentially profitable contract negotiations, which effectively prevents them from speaking out at a meeting while negotiations are in progress.

The main effect of the Group B tactics has been to drive militancy underground. The governments of the 77 have become tired of the intransigence and prevarication they meet in UNCTAD, and individual delegates have become reluctant to be identified and harassed as troublemakers. Consequently, developing countries that are big enough, or that have sufficient bargaining power by virtue of their resources, avoid participating in any depth in UNCTAD debates and quietly go ahead and take unilateral action. The Latin American countries, for example, have maintained a low profile in UNCTAD debates on cargo entitlements for national fleets while passing their own cargo reservation laws. Countries in Africa and Asia are now doing the same.

However, the failure of the 77 to attack the existing economic order more vigorously can only be partly explained by the manner in which the 77 militancy has been driven underground. After all, comparatively few of the members of the 77 have sufficient commercial strength to be able to act unilaterally, and even the strongest of them can take only a limited amount of unilateral action. For a true explanation, one must look deeper than the superficial conflict between rich and poor countries and examine the underlying conflict between rich and poor people. For the status quo does not so much benefit rich countries as rich people, whether they are in rich or poor countries.

\section{Rich people and the status quo}

There is a strong community of interest between the rich people of the rich countries and the rich people of the poor countries. The governments of poor countries are virtually all controlled by rich people, who have more in common with the rich people who control the Group B corporations than they have with their own poverty-stricken fellow countrymen.

usually try to have representatives attached to their government delegations. The extent of the influence of such business interests has been the subject of specific comment in UNCTAD (see the secretariat report Open Registry Fleets, TD/B/C.4/220 [Geneva, 3 March 1981], especially p. 15). Prior to UNCTAD V, the secretariat made a very limited proposal for cargo-sharing in regular bulk traffic with developing countries. As the concept of cargo-sharing had already been accepted in the liner trades (which are regular), it would have been difficult to oppose this proposal on grounds of logic or equity. Nevertheless, an association of tanker owners circulated counterarguments against a so-called "UNCTAD proposal to introduce cargo-sharing into all bulk trades." As most bulk trades are irregular, the association had no difficulty in painting an horrific picture of the practical difficulties that would arise. By exaggerating proposals, business organizations can strengthen the arguments against any international action whatsoever. 
In international warfare, there is universal contempt for quislings, those who work with occupying forces to the detriment of their nation's interest. In international business, however, it is quite common for economic quislings to assist foreign corporations to exploit their own countries. Such people exist in all countries, but it is in the poor countries that the results are so tragic.

It is in the national interest of a poor country to pay as little as possible for imports and services such as shipping, to obtain as much as possible for exports, and to obtain the greatest possible involvement of its nationals in ventures operated by transnational corporations on its own territory. However, economic quislings will agree to pay more than necessary for imported goods and services (or agree to unnecessary imports) and to accept less than necessary for exports, and will allow a corporation to treat their country like an economic colony-provided that they themselves are "looked after" by the corporation. In fact, the main reason why the rich of the rich countries are so successful in maintaining their grasp on the world's wealth and wealth-producing activities is that there are so many rich and would-be-rich people in the poor countries who are only too willing to collaborate with them. "Economic colonialism" depends just as much upon economic quislings as upon economic imperialists.

Once one perceives the underlying labyrinth of personal interests and pressures, it becomes apparent that the formal debates between rich and poor countries in UNCTAD are little more than mock battles between the rich people of the rich countries and the rich people of the poor countries, stage-managed by the rich people of the secretariat. All of the participants have a vested interest in seeing that UNCTAD does nothing to change the status quo.

Yet none of them would want to see the organization abolished. If UNCTAD did not exist, it would be harder to resist pressures to set up some other organization, one that might turn out to be effective. As things stand, the leaders of the rich countries can pacify some of their left-wing pressure groups by talking about their efforts in UNCTAD to help the poor countries, and the rich leaders of the poor countries can talk about their efforts in UNCTAD to obtain a greater share of the world's wealth for their people. Though established to help poor countries, UNCTAD has ended up by serving the interests of rich people.

It is impossible to solve the international problem of poverty without tackling the issue of rich and poor people-and yet the question of personal enrichment is one that simply cannot be raised, let alone answered, in international bodies. Any attempt to raise this issue meets objections on the grounds that such questions constitute unjustifiable interference in the domestic affairs of sovereign states. At UNCTAD V, the people who met in such lavish conditions to discuss world poverty all behaved as if they believed 
the maldistribution of personal wealth to be totally irrelevant when considering the maldistribution of international wealth.

In actual fact, nothing could be more relevant. The reason is obvious: governments and corporations that oppose any redistribution of the world's wealth are all controlled by people, people who are in a position to reward those who do them favors and to exert pressure on those who do not. When people fight to preserve the wealth of their country or their corporation, it is because they expect to be rewarded for their efforts. The rewards sought by the UNCTAD delegates who defend the status quo (or who refrain from attacking it) are relatively modest: they are just bureaucrats who are seeking promotion. But the delegates are only the tentacles of a vast hierarchy of vested interests, headed by people whose rewards from the status quo are very substantial, and who can offer substantial rewards to those who cooperate with them and exert substantial pressure on those who do not. Indeed, it is impossible to understand the failure of the North-South debate merely by examining the substantive issues; one must look at the underlying labyrinth of personal interests and pressures.

So long as people are free to enrich themselves excessively, they will continue to apply excessive pressure to preserve a status quo that enables rich people to get richer. The failure of the North-South debate can ultimately be traced back to the failure to curb excessive personal enrichment. The machinery for dealing with North-South issues will continue to fail so long as it is geared to do no more than examine the superficial issues between rich and poor countries.

\section{The failure to curb excessive personal enrichment}

However, while excessive personal enrichment cannot be curbed by international action, it is also the one issue upon which absolutely no initiative can be expected from national policy makers. The reason is simply that anyone who is sufficiently powerful to influence national policies is inevitably well-to-do, if not rich-someone who has already collected a fair share of the rewards and who is hoping for more. And there are very few politicians or civil servants in the world who want to abolish their own perks and privileges. Even leaders of trade unions and left-wing political parties become rather attached to the joys of living at the top. Outside the circles in which government policies are formulated, the effects of excessive personal enrichment are largely unstudied. Scholars steer well clear of the subject, perhaps out of fear of offending people who could help their future careers.

Certainly, there has been public comment on Third World elites who enrich themselves while neglecting their communities, but always with the innuendo that this is a problem endemic to developing countries. Yet it is obvious to anyone who has moved around in the bureaucracies of business, 
industry, and government that exactly the same thing is occurring in the industrialized countries, albeit in a less blatant form.

High salaries, status symbols, and fringe benefits have ceased to be rewards for competence and effort and have become ends in themselves. They divert administrative and managerial talent away from the task of improving the productive capacity of society and into incessant power struggles to get to the top, creating a whole new breed of power-seekers who are more competent at manipulating themselves into well-paid, prestigious positions than they are at performing the functions involved. The worst aspect is that government planning officers, whose sole function should be to determine what is best for their country, have become notorious for favoring policies that will maximize their own roles and minimize those of their rivals. Whether the policies happen to be good or bad for the country has become a secondary consideration. The same applies a fortiori to the planners in international organizations.

It is true that the money spent "rewarding" the top people would make little difference to the standard of living if redistributed in cash throughout the community. However, it would make a significant difference if invested on the factory floor to increase productivity and improve working conditions. Moreover, people who are free to use their decision-making powers to make life comfortable for themselves soon cease to care how comfortable or uncomfortable life may be for the rest of the community, and the money they siphon off for lavish living arouses the hostility of the work force. A hostile work force, in turn, discourages outside investment. Thus, the failure to curb excessive personal enrichment, whether in rich or poor countries, ultimately leads to poor national planning and administration, mismanagement, a hostile work force, and insufficient investment-a perfect formula for failure.

Given the vested interests, though, if there is to be any revolt against excessive personal enrichment it could only come from outside the established corridors of power. Such a revolt, in fact, could only come from the sort of popular pressures that stopped the war in Vietnam and forced governments to take up issues of human rights.

The need for some such revolt is greatest in the poor countries, for they suffer from the greatest gap between rich and poor people, the greatest economic failures, the greatest instability, and the greatest lack of investment. The inequitable distribution of wealth within poor countries also provides rich countries with a sound reason for refusing aid, since they can argue that benefits would only end up in the hands of the ruling elites. In fact, aid to the Third World has been cynically defined by some disillusioned field experts as "taxing money out of the pockets of the poor of the rich countries in order to fill the pockets of the rich in the poor countries."

However, it is in the poor countries that such a revolt is least likely to occur, because most of them lack the democratic structure needed for popular protests, and most lack the middle classes of reasonably educated people 
from whom such protests are most likely to arise. In any event, it is the rich of the rich countries who set the basic pattern for lavish living-at-the-top. If excessive personal enrichment were to be forced out of fashion in the rich countries, it would soon cease to be the fashion elsewhere.

\section{The decline of the North-South debate}

The North-South debate is fading toward oblivion because the conflict between rich and poor countries was never really the fundamental issue, and the debate has now reached the point where the participants can no longer pretend that they are making progress. Initially, the debate had a strong appeal to those who felt motivated to do something about poverty, but after years of talking the poverty continues.

The basic problem in tackling poverty is that one cannot examine the question of poverty unless one also examines the question of wealth-though that is just what national politicians try from time to time to do by advocating a "war on poverty," whereby they can pander to public feelings of pity without pointing accusing fingers at their rich constituents. One might conceivably wage war on wealth, but to speak of waging war on poverty is meaningless. It is for this reason that wars on poverty invariably fade from public notice after the first flurry of political speeches.

Unlike wars on poverty, the North-South dialogue at least recognizes the relevance of wealth when dealing with poverty-but it is the delightfully vague wealth of the rich countries, or the even vaguer wealth of "the West." Treating the issue in terms of rich and poor countries implies that the poor countries (including their upper layers of very rich people) should enjoy a monopoly on world pity, while the rich countries (including their masses of poor people) should take all the blame. While it is common for countries to be called rich or poor if the majority of their citizens are rich or poor, it is the poverty of poor people, not poor countries, that should arouse sympathy, and it is the avarice of rich people, not rich countries, that calls for examination.

There will be no solution to the international problem of "poor countries" until governments take action to restrain excessive personal enrichment. And governments are only likely to take action if popular pressure forces them to do so. 